\title{
READING COMPREHENSION IN HIGH-POVERTY SCHOOLS: HOW SHOULD IT BE TAUGHT AND HOW WELL DOES IT WORK?
}

\author{
Elizabeth J Pretorius \& Mirriam Lephalala \\ Unisa
}

This article describes and appraises a reading comprehension programme that was aimed at Grade 6 learners and teachers and implemented in different ways in two high poverty primary schools where reading levels were very low. The programme was implemented during formal school hours at the one school, while it was offered after school as a voluntary afternoon activity at the other school. Because attendance of the voluntary programme was generally poor, the latter school served as a control site. The results of the comprehension programme for the learners' reading abilities in their home language, Northern Sotho, and in English are reported. On the basis of these findings, we evaluate the programme and identify 'lessons learned' from its implementation that may have relevance for future reading comprehension interventions.

\section{INTRODUCTION}

It is now generally recognised that there is a reading crisis in South African schools. The large-scale national systemic assessments commissioned by the Department of Education during the past decade for the assessment of literacy and numeracy at Grade 3 and 6 levels have, since they were first made public, shown alarmingly low literacy levels (Department of Education, 2003, 2005). Yet, to some extent, the nature of the literacy problem was masked by the language issue, since the majority of the Grade 6 learners did the systemic assessments in English, a language that was not their primary language.

When the results of the Progress in International Reading Literacy Study (PIRLS) 2006 were released in November 2007, they forcefully brought home the message that South African learners have reading problems irrespective of the language in which they read. Of the 40 participating countries, South Africa not only came last, but also came badly last. The PIRLS 2006 tests were conducted in all official South African languages, with the Grade 4 learners completing the reading test in the language in which they had done their Foundation schooling. The top performing countries were the Russian Federation, Hong Kong and Singapore, with 565, 564 and 558 points respectively. The PIRLS international average was 500 points, while South Africa had 302. A disaggregation of the results showed that Grade 4s who did the reading test in English obtained 346 (of whom 60\% were English second language users) while those who did the tests in their African language performed most poorly of all: Tswana was the highest at 252 and Ndebele the lowest at 176 (Howie, Venter, Van Staden, Zimmerman, Long, Du Toit, Scherman \& Archer, 2008). 
In PIRLS 2006, four aspects of comprehension were tested, namely a reader's ability to

- retrieve explicitly stated (literal) information from a text

- make straightforward inferences from information given in a text

- integrate ideas and information across the text

- examine and evaluate the text (Mullis, Kennedy, Martin \& Sainsbury, 2006).

The international norm showed that $94 \%$ of learners could answer questions that required the retrieval of explicitly stated information. In contrast, in South Africa only $12 \%$ of Grade 4 learners could answer questions at the first, literal level. In other words, $78 \%$ of our Grade 4 learners did not meet minimum comprehension standards, and they could not answer such questions when reading in the African languages (Howie, Venter \& Van Staden, 2008).

The bottom line is that it is literacy that determines successful schooling, not language. One cannot assume that if children speak a language, they automatically become literate in that language or that reading in that language will come naturally and that they will easily understand the texts that they read. Language is the vehicle through which and in which reading is done, but in whatever language children do their schooling, reading needs to be a central school activity; it needs to be taught well and it needs to be meaningful. To its credit, the Department of Basic Education initiated the Foundations for Learning programme in 2008 in an attempt to raise literacy levels, and various provincial departments have also implemented literacy initiatives. The Gauteng Primary Literacy Strategy (2010-2014) is targeting 792 low-performing schools in the province to improve literacy teaching and ensure that $60 \%$ of the learners perform at $50 \%$ and above (Gauteng Department of Education, 2010).

South African learners' poor performance in reading comprehension clearly indicates that comprehension needs attention. But this naturally begs a host of questions involving what, how, how much? In addition, we also need to ask ourselves How do we know if what we are doing really works?

In this article, we describe a reading comprehension programme for Grade $6 \mathrm{~s}$ that was implemented in two high-poverty primary schools in slightly different ways. We look at the two different schooling contexts and the effect this programme had on the learners' reading performance in Northern Sotho (henceforth N Sotho) and in English. We use the findings to identify 'lessons learned' from its implementation. Before moving on to the study itself, we take a brief look at what is meant by reading comprehension and what research reveals about the teaching of reading comprehension.

\section{READING COMPREHENSION}

In order to be able to teach comprehension, we need to have a fairly good idea of what we mean by the term so that we can make sure that our teaching actually achieves its goal. In other words, a comprehension instructional programme needs to have construct validity. Any approach to teaching reading comprehension should thus be informed by a theoretical model of reading.

In this study, the notion of 'comprehension' is described and situated within a socio-cognitive model of reading literacy, in which reading is viewed as a highly complex phenomenon 
comprising many cognitive-linguistic skills and component processes that tap into various knowledge bases, all of which are embedded within a social matrix (Pretorius, 2010). The act of reading is thus both an individual cognitive-linguistic accomplishment, as well as socially constituted practice. In terms of the cognitive-linguistic aspect of reading, four main components are distinguished, irrespective of the language in which reading occurs, namely decoding, comprehension, response, and metalinguistic/ metacognitive knowledge. These components, in turn, comprise various subcomponents and all are highly interrelated. They are also embedded in an affective matrix that influences readers' perceptions of reading, their responses to text and their motivation to read. The whole intellectual accomplishment of reading is influenced by the social environment in which individuals grow up and enact their daily lives, where home, school, community and larger socioeconomic and political factors impact on the functions that reading serves, the attitudes and values attached to it and the way in which it is developed in institutions charged with its instruction and development (Pretorius, 2010:348). The four main components are briefly described below.

Decoding: Written text comprises a system of signifiers (for example, letters) that represent language below the level of the word. In alphabetic languages, these symbols represent the phonological level of languages. Decoding refers to the process whereby print symbols or codes are recognised and 'translated' or de-coded into language. Decoding skills, also referred to as lower level reading skills, include the reader's knowledge of sound-letter relationships in the alphabetic writing system; the ability to perceive and manipulate sounds within a linguistic sequence; and the ability to recognise words rapidly and accurately. Fluency refers to the ease, speed and accuracy with which reading takes place, following the natural rhythm of spoken language. Pikulski and Chard (2005) refer to reading fluency as the bridge between decoding and comprehension.

Decoding enables comprehension; if learners have difficulty decoding text, then comprehension is compromised. The early work on processing speed and reading fluency done in the 1970s by LaBerge and Samuels (1974) paved the way for more detailed research into the relationship between lower level decoding skills and higher level comprehension and processing principles, such as allocation of attention and automaticity. Practice increases the speed with which the lower level processes are executed and this results in the allocation of attention to higher level comprehension processes. Bringing together insights from both connectionist and information-processing models, Wolf and Katzir-Cohen (2001:219) provide a developmental view of fluency, with mature fluency referred to as 'a level of accuracy and rate where decoding is relatively effortless; where oral reading is smooth and accurate with correct prosody, and where attention can be allocated to comprehension'.

Besides internal factors (individual variations in children's phonemic awareness and central processing mechanisms) there are also external factors (teaching methods, exposure to texts, opportunities to practise, motivation and encouragement to engage in reading) that determine how well children's decoding trajectories develop.

Comprehension: Comprehension is what reading is all about. More technically, comprehension is the overall process of assigning meaning to the text that we read, whether it is a one-line advert or a lengthy novel. Current theories of reading comprehension posit that, while we read, we construct an overall picture of what the text is about, referred to as a mental model and or text representation (Koda, 2007; Kintsch, 2004). Construction of meaning during reading is dynamic; the mental model continually changes or gets updated in response 
to new incoming information from the text and the background knowledge that the reader brings to the reading process.

The ability to resolve anaphors across sentences and paragraphs, make inferences, identify text macrostructures within different genres and use background knowledge to make sense of text are all aspects of comprehension. Vocabulary knowledge is an important component of comprehension and correlates very highly with it (National Reading Panel, 2000). However, vocabulary is a necessary but not a sufficient condition for reading comprehension; the meaning of a text is not the sum of its words. Because much of what we read, especially when reading to learn, also deals with new, previously unknown information, we must be able to interact with a text in such a way that we can modify existing knowledge or acquire new awareness and knowledge in the process.

Response: Reading is not a neutral act. When we comprehend a text, we react to it in some way (e.g. with delight, curiosity, boredom), even though we may not be consciously aware of our reaction. Readers' responses to text are closely tied up with their affective dimension, their feelings, attitudes, perceptions and values. The more positive the initial attitude is to reading, the more likely a reader will initiate an act of reading, enjoy it, engage with the text and derive some emotional and/or intellectual benefit from it. If learners experience reading as a slow and effortful process that yields little by way of comprehensible outcome, then the cognitive-linguistic effort bears few, if any, emotional or intellectual dividends. As Wolf points out, emotional engagement is 'the tipping point between leaping into the reading life or remaining in a childhood bog where reading is endured only as a means to an end' (2008:132).

Metacognition: This is about awareness and regulation; it involves the ability to reflect on language and thinking and to act on them when required. It can be applied to any component of reading viz decoding, comprehension or response aspects of reading. Good readers use metacognition to monitor their comprehension, to repair failed comprehension and to distribute attentional resources. Numerous studies have highlighted the benefits of explicit reading strategy instruction for increasing metacognitive awareness and regulation in both L1 and L2 readers (Israel, Block, Bauserman \& Kinnucan-Welsch, 2005).

At whatever age group it is aimed, a reading comprehension instructional programme should target those skills, processes and knowledge bases that are central to text comprehension, but it should also be sensitive to readers' decoding abilities, and it should also aim to tap into and build up the response and metacognitive components of reading, since these enable, support and regulate comprehension.

\subsection{Teaching reading comprehension}

The PIRLS 2006 results indicate that our learners have problems making sense of the texts that they read. This suggests that comprehension itself is receiving little attention in classrooms. If comprehension is essentially about constructing meaning while we read, then we need to teach learners to engage with the text; to apply those kinds of strategies that enable meaning construction before, during and after reading; and to apply repair strategies whenever meaning falters, be it at the word, sentence or paragraph level. As Block and Pressley point out, reading meaningfully is a 'habit of mind we want students to internalise and use forever' (2007:235), and this should be the goal of comprehension instruction. 
Research findings show that, when learners are explicitly taught how to engage with a text and how to read in a more strategic manner and when these reading behaviours and strategies are modelled for them, then their comprehension levels can improve (Bridge, 1987; Pearson \& Fielding, 1991; Ruddell, 1994; National Reading Panel, 2000; Block \& Pressley, 2007). As to what to teach, Block and Pressley (2007:225-226) identify nine instructional principles:

- helping students attend to words and derive meanings from new words using textual and morphological clues;

- using previewing strategies before reading to activate appropriate schemas and make predictions;

- $\quad$ asking questions, making predictions and interpretations while reading; noticing when comprehension breaks down and re-reading sections of text when this happens;

- using setting, characters and story grammar elements to comprehend a narrative text;

- using text features and genre conventions (headings, diagrams, captions, sequence) to help understand informational texts;

- connecting ideas in a text to personal experience, background knowledge and other text information;

- summarising a text afterwards;

- reflecting on a text after reading.

With regard to how to teach comprehension, research points to explicit instruction for each strategy as being most effective. In addition, teachers are advised to model strategies aloud so that learners can see how they are used by expert readers, with learners gradually taking over the actions. Learners should also be encouraged to name the strategies aloud so that they develop a metadiscourse with which to talk about text and become aware of their own comprehension, thinking, inferring and reasoning processes. Finally, Block and Pressley (2007) suggest the regular re-teaching of strategies in either large or small groups to make sure that learners remember to use them, and the integration of all the necessary strategies in a single lesson so that learners 'may be shown how to view their comprehension and metacomprehension as a unified self-controlled ability' (2007:230).

\subsection{Research focus}

The comprehension intervention in this study was aimed at Grade 6. A larger literacy intervention, the Reading is FUNdamental project, had been operative at the school for two years already (cf. $\$ 3.1$ below for more information about this project) and so we were aware of the low reading levels at the school. On the assumption that learners need to be taught how to read texts in ways that will help them to enjoy and understand what they are reading, it was decided to focus on narrative texts, since this genre would be the most familiar to the learners and the easiest by which to induct them into active text engagement. It would also be easier to tap into the response component of reading via narrative texts. In order to assess the impact of the programme, a quasi-experimental, pre- and post-test design was used. The second project school in the same township with similar schooling conditions served as a control school.

The intervention was conducted once a week in English during a single period for two and a half terms. We were interested to see whether explicit comprehension instruction could make a difference despite the resource limitations of the schooling context and the brief instructional period. Additionally, we were interested to see how the Grade 6 language teachers responded to the intervention programme. However, the uptake of the programme by 
the teachers is not the focus of this article. Instead, the three research questions that inform this article are as follows:

1. Did the English and N Sotho reading comprehension abilities of the Grade 6 learners improve in the two schools as a result of the programme?

2. Were there differential effects in the comprehension performance of the learners?

3. What was the relationship between decoding and comprehension?

Finally, on the basis of our findings, we consider what lessons were learned and what modifications or alterations could be made to the comprehension programme.

\section{RESEARCH METHODOLOGY}

In this section we describe the two schooling contexts that served as control and intervention sites, the participants, the nature of the reading programme and the test instruments.

\subsection{The research context}

Two high-poverty primary schools in Atteridgeville township, west of Pretoria, were involved in a 5-year longitudinal literacy intervention, the Reading is FUNdamental project. This was a multi-level project that aimed to improve learners' school performance through literacy development, by building resources and capacity in high-poverty primary schools. In the resource-building component of the project, the focus was on helping each school establish a functional school library, reclaiming rooms at each school that had previously served as storerooms, computerising the library lending system, training a young person from the local community to serve as the school librarian, helping the school build up library stock, ensuring that learners had easy access to books and encouraging teachers to create print-rich environments in their classrooms (Wessels, 2010).

The capacity-building component of the project focussed on developing the instructional capacity of the teachers and the supportive capacity of the parents. Workshops were held fortnightly with the teachers after school during which the focus was on reading and information literacy. The aim was to increase teachers' understanding of the reading process; familiarise them with reading strategies; draw attention to OBE assessment standards for reading and different ways of assessing reading at the various grade levels; and integrating the library into their classroom practices. Family Literacy workshops were also held twice a year on Sunday mornings to encourage parents to become more actively engaged with their children's literacy development.

The comprehension programme described in this article (described in detail in $\$ 3.3 .1$ below) was one aspect of the capacity-developing component of the larger project. The school where the comprehension programme was implemented on a voluntary after-school basis serves as the control cohort, while the school where the comprehension programme was implemented during the formal school timetable forms the intervention cohort. Conditions at both schools were similar in many respects in terms of school size, inadequate resources, shabby buildings and few print-rich classrooms. Both schools also had feeding schemes. However, they differed in terms of two factors, namely quintile status (poverty level category) and language policy. 
The control cohort: The school with the Grade 6 learners who comprised the control cohort is a non-fee Quintile 1 school $^{1}$. The school has over 600 learners and a staff of 16 teachers plus the principal, two administrative staff and a janitor. The school serves a socio-economically disadvantaged community with many learners coming from informal settlements. There are two classes at each grade level. N Sotho is the initial language of learning and teaching (LoLT) from Grade R to Grade 3. In Grade 4, English becomes the LoLT while N Sotho becomes a subject of instruction from Grades 4 to 7 . Although many children come from homes in which a variety of African languages are spoken, about $70-80 \%$ of the learners at this school come from primarily N Sotho-speaking homes (the numbers fluctuate somewhat from year to year). In 2008 there were two Grade 6 classes comprising 77 learners in all.

At the time of this study, the library at this school had about 4,500 books in its collection. Most of these were English books; at the time there were about 180 titles in N Sotho (many with multiple copies) in the library, most of them storybooks for children up to the age of about 10 years. Despite the project's policy to buy as many N Sotho books as possible, there was very little adolescent fiction for 11- to 14-year olds in N Sotho, and practically no nonfiction books available from the various publishing houses.

The intervention cohort: The school with the Grade 6 learners who comprised the intervention cohort is a Quintile 3 school. Although the school has been assigned Quintile 3 status, the school buildings are shabby and the school serves many children from informal settlements. The principal has applied for a reassessment of the quintile status of the school on the grounds that it is an inaccurate assessment of the social and financial capital of the school. The school has about 580 learners and a staff of 16 teachers, two administration officers and a janitor. This school has a straight-for-English policy: in other words, English is used as the language of learning and teaching from the Foundation Phase till Grade 7; N Sotho is taught as a home language from Grades 2 to 7 . Here, too, there are many children from homes in which a variety of African languages are spoken, but about $60-70 \%$ of the learners at this school come from primarily N Sotho-speaking homes.

At the time of this study, the library at this school was a bit smaller (having started a year later), with a collection of about 2,600 books. Here too, most of these books were in English; at the time there were only about 120 titles in N Sotho.

\subsection{Participants}

There were two classes at each grade level in both schools. There were 77 learners in the control cohort class and 72 in the intervention cohort. The mean age across all the participants was 12 years. The youngest was 11 and the oldest 15 .

\subsection{The reading comprehension programme}

Two members of the project team (the authors of this article) worked closely with the Grade 6 learners and teachers at the intervention school once a week. The aims were twofold, targeting both learners and teachers, but this paper focuses only on the learner aim:

- to work directly with the learners, stimulate their interest in reading and to improve their reading comprehension through various focussed reading activities. 
The last period on a Thursday was used to operationalise the above aims. This period, named 'The Book Club', was obligatory, occurred during school hours and involved the whole class and the teacher.

\subsubsection{The main elements of the programme}

Pre-tests conducted at the beginning of the first term showed that the Grade 6 learners, on the whole, had very low reading comprehension levels (cf. results in $\$ 4$ below). Most of the learners were not familiar with storybook reading and came from homes with few print-based resources and where shared storybook reading did not occur. Rather than try to do too much, it was decided to teach six basic narrative comprehension elements and to repeat them in various ways and with different texts during the ensuing months to develop 'a habit of mind'. These were:

- identifying the main elements of a story, also known as 'story grammar' (e.g. setting, characters, problem, events, resolution to problem, theme of story);

- using a few reading strategies such as previewing, taking note of new words and their structure and finding out meanings;

- asking "I wonder ..." questions to engage attention and help make text connections ( $I$ wonder what will happen next? I wonder what this word means? I wonder why the writer wrote it like that?);

- re-reading to clarify understanding;

- looking at response to texts, i.e. how stories tap into our emotions (what did I feel while I was reading?);

- looking at how language is used in stories (e.g. repetition and onomatopoeic words in children's stories, past tense to convey story, etc.).

Initially, the texts used during the Book Club period were short and easy texts, intended for younger learners. It was important for the texts to be accessible to the learners so that the meaning-based approach could be understood. Although a formal instructional approach was used, an attempt was made to keep the period fun and interesting for the learners.

The Book Club programme started halfway through the first term and ended at the end of the third term. By March, each learner was issued with a 48-page A5 exercise book which was titled Book Club. The learners were expected to bring this book along each Thursday for various note-keeping activities; to record new words; to paste in copies of stories read in class; and to write down the titles of books read. They were also encouraged to purchase a dictionary (English or bilingual English/N Sotho) and bring it to their Book Club period (but very few learners had their own dictionaries). The researchers brought copies of two bilingual NS/English dictionaries and two student Oxford dictionaries for class use each week.

The teachers did not have multiple copies of readers for the Grade 6 learners and the school library was not yet operational for older learners in the second term. It was therefore decided to provide Photostat copies of stories for each period and to use these stories to focus attention on a particular aspect of text/reading each time. The learners pasted these copies into their Book Club exercise books. The Book Club went through three different phases, in response to the school and classroom situations, as outlined below. 


\section{I: The Intensive reading phase (February - April)}

In an intensive reading programme, the teacher explicitly draws learners' attention to various aspects of a text or a reading strategy by explaining, modelling, getting the learners to engage with the text and providing opportunities for practice. There are several research findings that indicate that this approach has beneficial effects on learners' comprehension, vocabulary and metacognitive awareness during the reading process (Day \& Bamford, 1998).

Activities varied between whole-class participation, group work and individual work. The class was divided into six groups, based on the seating arrangements in the classroom. For each period, a lesson plan was drawn up which was given to the Grade 6 teacher before the start of the period. Each lesson also included the following features:

- A recap of the main ideas of the previous lesson.

- Pre-reading activities (including discussion of title, author, pictures, making predictions about what the story may be about, etc.).

- Asking learners to identify new words and drawing attention to their structure (for example nouns/verbs, prefixes/suffixes), thereby encouraging self-efficacy through the habit of identifying and focussing on 'new' words and finding out what they mean.

- Writing up on chalkboard at least five new words important for the story and giving $\mathrm{N}$ Sotho equivalents, which the learners were expected to write in their exercise books.

- Encouraging learners to use dictionaries (copies of English and NS/English dictionaries brought to class each week); using enthusiasm to make this a fun, interesting activity.

- Identifying the main story elements (main characters, setting, problem, events, resolution, theme).

- Identifying specific prominent language elements in the texts.

An example of a typical lesson plan for this approach is provided in Appendix A.

Because the learners were not working with real books, it was important that they valued and properly managed the copies of text handed out each week. Pairs of scissors, several sticks of glue and extra pens were supplied in 'Book Club' plastic containers that were passed around class for learners to stick their handouts into their books. Time was also set aside each period for the 'cutting and pasting' to take place, so that copies of stories were not lost.

Initially, the texts were only about 200 to 400 words long. It was important for the learners to be exposed to reading stretches of extended texts and to hear such texts being read fluently and with expression. It was also important to show them that re-reading a text several times was allowed, that re-reading difficult or tricky parts was an important part of the reading process and to remind them that each re-reading brought greater understanding. Thus it was not uncommon for a story to be read three or even four times in a lesson, first by the researcher/teacher; after new words had been explained and the story discussed, it was re-read again aloud by the researcher/teacher with fluency and feeling, and then again by the learners, with individual learners or groups taking turns to read a paragraph at a time. At times, the learners were also given 6 to 8 minutes to read the story silently on their own, towards the end of the lesson, so that they could practise silent reading.

Although the Book Club lessons were conducted in English, the use of $\mathrm{N}$ Sotho was incorporated into the lessons so that the learners could draw on it as a resource to help them 
enjoy and understand stories and to encourage them to enjoy reading in their own language. The learners were not used to using a bilingual dictionary but soon started enjoying it. Some of the activities also required them to provide $\mathrm{N}$ Sotho equivalents for words or ideas that were discussed in the lesson. For example, after using the story The great big enormous turnip to illustrate the components of a story, the learners were given as homework, in their groups, the task of rewriting the story into N Sotho in booklet form and illustrating some of the scenes. The booklets were 'judged' by the second author of this article and the groups with the best translated story and the booklet with the best illustrations were given prizes.

\section{II: Thematic reading: Travelling the world through stories (May - June)}

Once the basics of story reading had been established a slight shift of focus was introduced, namely the theme of 'travelling the world through stories'. Each week a story written by an author from a different country/continent was read and discussed in class and copies were given to the learners. These stories were longer texts (about 800 words), more in line with the kind of extended text that Grade 6 learners should become familiar with. A large map of the world was bought and stuck onto the chalkboard at the start of each lesson, and each leaner was given an A4-size copy of the world political map to stick into their Book Club book. At the start of the story reading session, the learners had to find the country on their map and write it in their exercise book. The story reading session then followed along similar lines to that used in the first phase, with previewing, vocabulary and re-reading activities and the main elements of the story identified and discussed. An example of a typical lesson plan for this thematic approach is provided in Appendix B.

\section{III: Guided reading (third term)}

As we became better acquainted with the learners, it became increasingly apparent that, while many of them were enjoying the thematic approach, there was also a number of learners who appeared to participate in the activities but did not properly understand the stories. The texts were too long and challenging for them and they struggled to read them. A change in tactic was called for to accommodate the various levels of ability. The aim of the guided reading programme was to give learners opportunities to read in a supportive group with other learners who were at the same level of ability. The class was re-organised into six reading ability groups, based on their oral reading fluency (ORF) scores (cf. §3.4 below). Each group selected a name for itself that was appropriate for a book club (for example The Stars, The Invincibles). The main features of this approach were as follows:

- Groups could not be larger than 6-8.

- The learners in each group read texts or books that were at their level of ability.

- During the group work, attention was paid to silent reading, word building and reading aloud.

- The groups had to work together to support one another and to learn co-operatively from one another.

By now the library was fully functional and 40 plastic chairs had been purchased so greater use could be made of the library space. The two classes took turns to spend Book Club period in the library, with each group sitting together at their respective tables. Rules for behaviour were drawn up and printed on a cardboard sheet, placed with each group to remind them of group etiquette (Appendix C). The library by now had had various copies of short storybooks that were graded according to difficulty and colour coded. These were set aside by the school 
librarian for Book Club use. Before the start of each lesson, the books for each group were sorted and handed out to the groups when they came in. The teacher and researcher would move from group to group, listening to the reading and generally providing support and encouragement. The learners loved going to the library and the Book Club seemed to become more real to them when they sat in the library reading at their group tables. Due to strike action during the third term, the Book Club periods unfortunately did not occur with as much regularity as originally planned.

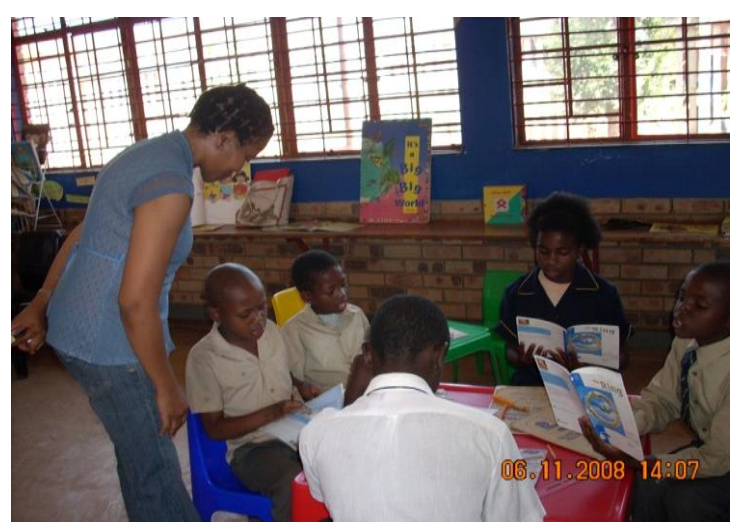

Left: Learners reading in ability groups in the library, facilitated by a project member

Unfortunately, the voluntary intervention at the control school did not work well. Attendance was erratic, especially amongst the weaker learners, and the Book Club was often cancelled due to after-school events.

\subsection{Test instruments}

All the Grade 6 learners at the school were given a reading comprehension test at the beginning (February) and end of the year (November). The test was first administered in English and three weeks later in N Sotho. The three-week interval between these tests was deemed long enough to reduce memory effects.

During the second term, the Grade 6 learners in the one class of the intervention cohort were assessed individually for ORF in English. Unfortunately the second Grade 6 class was unable to be assessed for ORF due to strike action at the school.

Reading comprehension: N Sotho and English reading proficiency was operationally defined as proficiency obtained in a reading comprehension test where a combination of test items was used for narrative texts. The text passages were taken from various existing Grade 6 textbooks. The test items included a combination of multiple choice questions of an inferential nature, vocabulary questions, cloze items, identifying referents of anaphoric items, and questions involving graphic information, e.g. maps, graphs.

The ability to answer inferential comprehension questions rather than literal questions is a reliable indicator of how well a reader understands a text (Oakhill \& Cain, 1998). While there were no literal questions, the majority of questions were a mix of straightforward and more cognitively demanding inferential questions; two interpretive comprehension questions were also included.

In the cloze task, approximately every 9th word was deleted, if it was appropriate and could be inferred from the text. Although the same passages were used in English and N Sotho for 
the cloze activities and the same number of deletions was designed, the same linguistic items were not deleted. Deletions were guided by the textual clues provided by the morphosyntactic and semantic features of each language text.

The ability to resolve anaphoric references in a text is an integral part of reading skills (Webber 1980). Specific anaphoric items were identified and the learners were required to underline the referents to which they referred. This section of the text was carefully explained to the learners beforehand in the test language, with an example on the chalkboard.

Oral reading fluency $(O R F)$ : The ability to read texts fluently, i.e. at an appropriate rate, accurately and with expression, is an important component of reading ability. ORF is an assessment tool that focuses on two of the three components of fluency, namely, rate and accuracy. It is based on a score obtained for the number of words read correctly in a minute from a previously unseen passage. In this case, the passage was taken from a short story about a young man who wants to become a taxi driver, so the topic was one that was familiar to the learners.

The learner was told that $\mathrm{s} / \mathrm{he}$ would need to read a passage aloud for a minute. The learner was first shown the passage, read the title aloud, looked at an accompanying picture of a minibus taxi and answered two or three informal questions about the picture and the title. The learner then read the passage from the original text for a minute, during which time the researcher followed the reading of the passage on a copy sheet and ticked words and punctuation that were read incorrectly or ignored. At the end, the number or errors were subtracted from the total number of words that the learner read during the minute. This gave a score of words read correctly per minute (WCPM).

\section{RESULTS}

Did the reading comprehension programme work and did it have beneficial effects on the learners' reading abilities? To test whether the Grade 6 cohorts at each school were similar at the start of the programme, Levene's test for homogeneity was applied to the comprehension scores at pre-test time. The results showed no statistically significant difference between the schools on this measure $(\mathrm{F}=1.56, p>.213)$. In other words, the two cohorts showed equality of variance before the intervention started.

The first research question was: Did the English and N Sotho reading comprehension abilities of the Grade 6 learners improve significantly in the two schools? Table 1 shows descriptive statistics with regard to the means, standard deviation and minimum and maximum performance at pre-test (March) and post-test (November) times. As can be seen, reading comprehension levels at pre-test time were very low at both schools in both $\mathrm{N}$ Sotho and English. 
Table 1: Grade 6 pre- and post-test comprehension scores for N Sotho and English

\begin{tabular}{|l|cc|cc|}
\hline \multirow{2}{*}{ Grade 6 } & \multicolumn{4}{|c|}{ Comprehension } \\
& Pre & Post & Pre & Post \\
\hline Control Grade 6 $(\mathrm{n}=78)$ & & & & \\
Mean age 12.1 years & & & & \\
& & & & \\
Mean comprehension \% & 31.9 & 34.2 & 35.3 & 32.0 \\
(Std dev) & $(16.92)$ & $(20.18)$ & $(16.03)$ & $(18.70)$ \\
Minimum-maximum \% & $0-69$ & $2-84$ & $9-78$ & $2-90$ \\
& & & & \\
Intervention Grade 6 $(\mathrm{n}=72)$ & & & & \\
Mean age 11.9 years & & & & \\
& & & & \\
Mean comprehension \% & 31.4 & 35.2 & 36.4 & 44.8 \\
(Std dev) & $(15.40)$ & $(15.83)$ & $(13.83)$ & $(23.61)$ \\
Minimum-maximum \% & $6-65$ & $6-70$ & $3-66$ & $6-88$ \\
\hline
\end{tabular}

The control cohort showed variable performance from pre- to post-tests: while comprehension in $\mathrm{N}$ Sotho increased marginally, a paired t-test showed this to be not significant $(\mathrm{t}=-1.259$ (df, 73) $\mathrm{p}=0.212$ ), and the mean in English comprehension actually decreased. On the other hand, the intervention cohort showed a small albeit non-significant increase in $\mathrm{N}$ Sotho comprehension $(\mathrm{t}=-1.953(\mathrm{df}, 67) p<0.055)$ and a large and significant increase in English comprehension $(\mathrm{t}=-4.146(\mathrm{df}, 71) p>0.000)$ between pre- and post-test results.

In order to compare for significant differences between the control and intervention cohorts, independent sample t-tests were applied to the post-tests. Results showed that the differences between the two schools were not significant for $\mathrm{N}$ Sotho comprehension $(\mathrm{t}=.322(\mathrm{df}, 144) p$ $=0.741)$, but they were highly significant for English comprehension $(\mathrm{t}=3.642(\mathrm{df}, 144) p<$ 0.000). To measure effect size for reading comprehension in English, Cohen's $d$ was used (the pooled standard deviation was used: $d=\mathrm{M}_{1}-\mathrm{M}_{2} / \sigma_{\text {pooled}}$ ); the result was $d=0.60$, showing a large effect size (Becker, 2000).

In reply to the first research question whether the reading comprehension abilities improved, the answer is that only the English comprehension abilities of the learners at the intervention cohort improved significantly. In addition, there was a large effect size. Although the N Sotho comprehension scores improved slightly, at neither school were these changes significant.

The second research question probes differences between the learners, viz Were there differential effects in the comprehension performance of the learners? Performance (in percentages) at the $25^{\text {th }}, 50^{\text {th }}$ and $75^{\text {th }}$ percentile in both $N$ Sotho and English reading comprehension showed quite marked differences in terms of comprehension ability within and across schools, as reflected in Table 2. On the whole, the learners in all three ability groups in the control cohort either remained the same or actually performed more poorly at post-test time in both $\mathrm{N}$ Sotho and English comprehension. In contrast, the learners in the intervention cohort showed steady increases in both N Sotho and English. 
Table 2: Differential effects in pre- and post-test comprehension for $\mathbf{N}$ Sotho and English

\begin{tabular}{|l|ll|ll|}
\hline \multirow{2}{*}{ Grade 6 } & \multicolumn{4}{|c|}{ Comprehension } \\
& N Sotho & English \\
& Pre & Post & Pre & Post \\
\hline Control Grade 6 $(\mathrm{n}=77)$ & & & & \\
Mean \% & 31.9 & 34.2 & 35.3 & 32.0 \\
$25^{\text {th }}$ & 21.2 & 20.4 & 22.7 & 18.1 \\
$50^{\text {th }}$ & 30.3 & 29.5 & 33.3 & 27.2 \\
$75^{\text {th }}$ & 42.4 & 45.4 & 45.4 & 39.7 \\
& & & & \\
Intervention Grade 6 $(\mathrm{n}=72)$ & & & & \\
Mean \% & 31.4 & 35.2 & 36.4 & 44.8 \\
$25^{\text {th }}$ & 17.8 & 22.7 & 26.1 & 23.2 \\
$50^{\text {th }}$ & 28.1 & 36.3 & 36.3 & 43.7 \\
$75^{\text {th }}$ & 43.7 & 47.7 & 45.4 & 66.7 \\
& \multicolumn{4}{|c|}{} \\
\hline
\end{tabular}

In addition, Matthew effects were clearly evident (Stanovich 1986, Pretorius \& Currin 2010). There was a group of about 10 to 12 learners at the $25^{\text {th }}$ percentile who were performing extremely poorly at both schools and showed very little progress. In fact, in both schools none of the learners obtained $25 \%$ in the reading tests in either N Sotho or English. According to Elley (2001:231), children who do not obtain $25 \%$ for a reading test are considered to be nonreaders. The non-readers at both schools showed little reading development during the year and remained non-readers; in effect, the poor remained poor. In contrast, while the middle group of learners in the intervention cohort showed some increases, the learners who responded best were the stronger learners at the $75^{\text {th }}$ percentile - the rich got richer, and they got richer in English comprehension. Pearson Product Moment correlations showed robust relationships between pre- and post-test comprehension performance in N Sotho and English respectively $(\mathrm{r}=.64, p<0.001$ and $\mathrm{r}=.66, p<0.001)$ as well as between comprehension in $\mathrm{N}$ Sotho and English $(\mathrm{r}=.67, p<0.001)$. In other words, good readers tended to stay good readers and weak readers remained weak readers across the year, and good readers in one language were also good readers in the other language, and weak readers were equally weak in both languages.

The third research question, namely What was the relationship between oral reading fluency and comprehension? helps to throw some light on the Matthew effects described above. As was indicated earlier, only Grade 6A at the intervention school was tested for oral reading fluency. Table 3 shows the descriptive statistics relating to reading comprehension and oral fluency for this class. 
Table 3: Oral reading fluency and reading comprehension

\begin{tabular}{|l|c|lc|}
\hline Grade 6A & $\begin{array}{c}\text { Oral reading fluency } \\
\text { Midyear }\end{array}$ & \multicolumn{2}{|c|}{ Reading comprehension } \\
& pre-test \% & post-test \% \\
\hline $\begin{array}{l}\text { Class mean } \\
\text { min-max }\end{array}$ & $76 \mathrm{wcpm} \dagger$ & 38.8 & 47.9 \\
& $5-124$ & $3-78$ & $6-88$ \\
$25^{\text {th }}$ & 42 & 27.2 & \\
$50^{\text {th }}$ & 84 & 39.3 & 25.5 \\
$75^{\text {th }}$ & 110 & 46.9 & 68.4 \\
\hline
\end{tabular}

$\dagger \mathrm{wcpm}=$ words read correctly per minute

A very robust and highly significant Product Pearson Moment correlation was found between ORF and reading comprehension: $r=.80, p<.000$, indicating a strong relationship between oral reading fluency and reading comprehension. This relationship is clearly reflected in the different percentiles shown in Table 3: the weak readers read slowly and haltingly; in fact they were reading at a reading rate expected of Grade 1 beginner readers, and their comprehension levels similarly were very low. The faster and more fluently that the learners read, the better they performed on comprehension. According to ORF norms in English, English children should be able to read at 90 wcpm by Grade 2, while Grade 4 children at the $50^{\text {th }}$ percentile should be able to read at 120 wcpm (Hasbrouck \& Tindal, 2006:639). Even the strongest readers in the class were not fluent readers. Not having sound decoding skills and reading slowly had a severely detrimental effect on the learners' ability to access meaning in the texts that they read.

\section{DISCUSSION}

One of the goals of the reading comprehension programme outlined in this study was to see whether a period set aside once a week for the reading and discussion of stories would improve the reading comprehension of Grade 6 learners in high-poverty schools. Was the programme successful in achieving this goal? The answer is yes and no, with accompanying qualifications. These, in turn, point to the complexities of the educational context within which learners and teachers operate on a daily basis.

To recap the main findings: When the programme was implemented during school hours, it had a positive effect on the intervention cohort, but only in English comprehension; the effects did not transfer to reading in N Sotho. Even in terms of English comprehension there were differential effects: although most of the learners showed increases in comprehension from pre- to post-test, the stronger readers showed the greatest increases while the learners at the $25^{\text {th }}$ percentile showed the least increases and some even regressed.

Despite differential effects, there was an overall increase of $8.4 \%$ in comprehension in the intervention cohort. However, the low comprehension mean was still a concern, and there was a big comprehension backlog to catch up. Considering that the majority of these learners would within a year from post-test time, be entering high school, very few of them would actually be able to cope with the literacy demands of high school, especially 'reading to learn' from content subject textbooks. 
The findings from this study also show that, when learners have not yet achieved decoding fluency and accuracy, it is difficult for them to apply and integrate comprehension strategies and knowledge when they read. So much time and effort is taken up trying to read (that is, decode) the text that very little cognitive energy is left for comprehension. The strong correlation obtained between ORF and comprehension ability obtained in this study confirms numerous other empirical studies. As Hasbrouck and Tindal (2006:636) argue, oral reading fluency is an 'accurate and powerful indicator of overall reading competence, especially in its strong correlation with comprehension'. These results suggest that, if children have very poor decoding skills, interventions that aim to improve comprehension are not going to be effective; a decoding intervention that runs concurrently with a comprehension intervention would serve the weaker readers better.

The weaker learners benefitted in the focussed reading groups, when they were put into smaller groups at their own ability level and given opportunities and encouragement to simply practice reading short texts aloud several times and to talk about words and pictures directly related to the sentences they were reading. This helped them more with decoding than comprehension. Although we did not formally test their ORF at the end of the year again, our informal impression was that all except two learners were reading slightly more easily and with greater confidence than when we had started. The two learners who did not respond at all seemed to have severe learning problems in general. They were at least $1 \frac{1 / 2}{2}$ years older than their peers and the teacher confirmed that they had previously been kept back a grade but were pushed through to the next grade even though they failed their subjects. There unfortunately were no educational psychologists to do diagnostic tests and no remedial programmes where they could receive greater support and specialist help.

\subsection{Lessons learned}

Having implemented a comprehension intervention for two and a half terms, it is important to identify what worked and what did not and to consider how it could be modified or changed. Content-wise, the elements that were included in the lessons (cf. §3.3.1) are theoretically and empirically well informed and comprise the kinds of activities that should be included in a comprehension intervention. The focus of our Book Club was primarily on reading stories (the narrative genre) because we felt that it was important to start with basic 'habits of mind' in a known genre. Yet Grade 6 learners need to be able to read both narrative and expository/informational texts, so that they can 'read to learn' from their content subject textbooks. Should more or fewer strategies be included, and how should an intervention like this be managed for maximum efficacy?

\subsubsection{Research considerations}

The study used general comprehension test items to see whether the learners read their texts with greater understanding. This is understandable, given that a comprehension intervention is intended to improve comprehension in general. However, it would have been helpful to examine more closely which aspects of the intervention the learners did internalise. For example, how well could they identify setting, characters, problems and resolution in a story; did they use previewing strategies before they started reading; did they use re-reading strategies on their own when comprehension failed; how many of the words they wrote up in their Book Club books had they internalised by the end of the year? The learners certainly enjoyed the Book Club periods, so it seemed to tap into their response levels, but did it improve their metacognitive awareness of reading? In future interventions we would like to 
find ways of assessing these elements of intervention programmes more directly, over and above assessing comprehension generally.

\subsubsection{Pedagogic considerations}

The 'habits of mind' that the intervention was attempting to instil are applicable to any age or grade level; the kinds of skills and practices we were teaching could equally be introduced in the Foundation Phase already, with age appropriate texts. However, a one-size-fits-all mindset must be avoided.

- It is important to adapt interventions to specific grades/classes at a particular point in time and in a particular context, with texts appropriate to the given classes. The classes in our study had low literacy levels, many children had very weak decoding skills, and the classes were not reading-homogeneous but comprised a wide range of abilities. In such cases, it is advisable to rather teach fewer strategies, and to include lots of opportunities for practice and repetition, to make sure that the new reading habits are internalised.

- When classes are not reading-homogeneous, it is important to organise different ability groups so that the learners can read texts appropriate to their level. This approach also requires firm class management - groups must learn to work well together; follow class procedures; and not be disruptive, noisy and off-task when the teacher is not near them.

- When overall performance is so low to begin with, attention must also be paid to the development of decoding skills. This must be done concurrently with comprehension, right from the beginning. Although an ORF test requires one-on-one testing, it is easy to administer and provides teachers with an accurate method of assessing and placing their learners in appropriate groups. The learners who were reading at only about 40 words a minute could not read, understand and discuss the texts that the faster and more accurate learners were reading. The weak readers only started responding to the intervention when they were given individual attention in their smaller groups with shorter, easier, texts.

- When learners initially have very weak reading literacy abilities, it is important for more time to be given to catch up. Implementing the intervention for one period a week was not enough. Weaker readers, in particular, need extra lessons and reading homework on a regular basis to help them improve their decoding skills. Whether these extra lessons are best built into the school timetable or done after school as a compulsory programme are decisions that schools need to take.

- Ideally, by Grade 6 comprehension interventions should also include strategies for reading other genres, such as informational or expository texts, so that learners can read to learn more effectively. The kinds of comprehension strategies that have been found to be useful for comprehending expository texts, such as identifying main ideas, drawing mind maps, summarising, identifying macrostructure, etc. also need to be included in comprehension interventions, especially after the Foundation Phase.

- Although vocabulary was incorporated into every Book Club lesson, more time was needed to build up the learners' vocabulary base and skills. Vocabulary building should be more than explaining the meanings of key words in given texts. Language periods should also be used for helping learners develop vocabulary learning strategies, in both the home language and in English.

- The intervention at the control school did not work well, mainly due to high absenteeism by many learners. The attendance by the teachers also was not regular, 
and the Book Club was often cancelled due to after-school activities. This suggests that, in poor performing schools, reading interventions should be compulsory and should be integrated into formal teaching times.

\subsection{Concluding thoughts}

Wolf describes reading as enabling us to move beyond the confines of our own thinking: 'While reading, we can leave our own consciousness, and pass over into the consciousness of another person, another time, another culture ... our original boundaries are challenged, teased and gradually placed somewhere new' (Wolf, 2008:7-8). A comprehension instructional programme should take learners beyond an effortful literal grappling with text, ultimately enabling learners to be 'somewhere new' and thus to experience the transformative power of reading.

A multiplicity of factors contributes to the successful implementation of a comprehension programme. These relate to the nature of the intervention programme itself, and to the learning and teaching context in which the programme is enacted. The comprehension intervention adopted in this study was theoretically and empirically well grounded. Although it yielded encouraging results, its application was not unequivocally successful. Some reasons for the uneven outcomes have been identified in this paper. A further paper focuses on the extent to which the programme was taken up by the teachers. It is hoped that upcoming interventions can build on the lessons learned here, so that future generations of readers can indeed be placed 'somewhere new' and empowering.

\section{END NOTE}

1. State funding for schools is now based on a quintile system (there are 5) according to socioeconomic indicators. Quintile 1 schools are the poorest, are non-fee paying schools and receive the highest state subsidy. Subsidy decreases the higher the quintile status.

\section{ACKNOWLEDGEMENTS}

Funding for the project was made possible by the DG Murray Trust and the NRF. The views expressed here are not necessarily those of the funders. Sincere thanks are also extended to the schools and Grade 6 learners who participated so generously in the intervention programme, thereby creating a space for research and pedagogy to come together to find some answers and to throw up new questions.

\section{REFERENCES}

BECKER, LA. 2000. Effect Size (ES). http:web.uccs.edu/lbecker/Psy590/es.html

BLOCK, CC \& M PRESSLEY. 2007. Best practices in teaching comprehension. In Gambrell, LB, LM Morrow \& M Pressley (Eds), Best practices in literacy instruction. New York: The Guilford Press.

BRIDGE, CA. 1987. Strategies for promoting reader-text interactions. In Tierney, RJ, PL Anders \& JN Mitchell (Eds), Understanding readers' understanding. Hillsdale, NJ: Lawrence Erlbaum.

DEPARTMENT OF EDUCATION. 2003. Systemic Evaluation 2003 Foundation Phase: Mainstream National Report. Pretoria, Department of Education. 
DAY, RR \& J BAMFORD. 1998. Extensive reading in the second language classroom. Cambridge: Cambridge University Press.

DEPARTMENT OF EDUCATION. 2005. Grade 6 Intermediate Phase Systemic Evaluation Report. Pretoria. Department of Education.

ELLEY, WB. 2001. Literacy in the present world: Realities and possibilities. In Verhoeven, L \& CE Snow (Eds), Literacy and motivation. Mahwah, NJ: Lawrence Erlbaum.

GAUTENG DEPARTMENT OF EDUCATION. 2009. Gauteng Primary literacy Strategy 2010-2014. Johannesburg, Gauteng Department of Education.

HASBROUCK, J \& GA TINDAL. 2006. Oral reading fluency norms: A valuable assessment tool for reading teachers. The Reading Teacher, 5:636-644.

HOWIE, S, E VENTER \& S VAN STADEN. 2008. The effect of multilingual policies on performance and progression in reading literacy in South African primary schools. Educational Research and Evaluation, 14(6):551-560.

HOWIE, S, E VENTER, S VAN STADEN, L ZIMMERMAN, C LONG, C DU TOIT, V SCHERMAN \& E ARCHER. 2008. PIRLS 2006 Summary Report: South African Children's Reading Achievement. Centre for Evaluation and Assessment, University of Pretoria.

ISRAEL, SE, C BLOCK, KL BAUSERMAN \& K KINNUCAN-WELSCH. 2005. Metacognition in literacy learning. Mawah, NJ: Lawrence Erlbaum.

KINTSCH, W. 2004. The construction-integration model of text comprehension and its implications for instruction. In Ruddell, RB \& NJ Unrau (Eds), Theoretical models and processes of reading. Fifth Edition. Newark: International Reading Association. 12701328.

KODA, K. 2007. Reading and language learning: Crosslinguistic constraints on second language reading development. Language Learning, 57(1):1-44.

LABERGE, D \& S SAMUELS. 1974. Toward a theory of automatic information processing in reading. Cognitive Psychology, 6:293-323.

MULLIS, IVS, AM KENNEDY, MO MARTIN \& M SAINSBURY. 2006. PIRLS 2006 Assessment framework specifications. Chestnut Hill: Boston College.

NATIONAL READING PANEL. 2000. Teaching children to read: An evidence-based assessment of the scientific literature on reading and its implications for reading instruction. Washington, DC: US Government Printing Office.

OAKHILL, JV \& K CAIN. 1989. Inference making ability and its relation to comprehension failure in young children. Reading and Writing, 11:489-503.

PEARSON, PD \& L FIELDING. 1991. Comprehension instruction. In Barr, R, MA Kamil, P Mosenthal. \& PD Pearson (Eds), Handbook of Reading Research, Volume II. London: Longman.

PRETORIUS, EJ. 2010. Issues of complexity in reading: Putting Occam's razor aside for now. Southern African Linguistics and Language Studies, 28(4):339-356.

PRETORIUS EJ \& SV CURRIN. 2010. Do the rich get richer and the poor poorer? The effects of a reading intervention programme on the home and the school language. International Journal of Educational Development, 30:67-76. 
PIKULSKI, JJ \& DJ CHARD. 2005. Fluency: Bridge between decoding and comprehension. The Reading Teacher, 58:510-519.

RUDDELL, MR. 1994. Vocabulary knowledge and comprehension: A comprehension process view of complex literacy relationships. In Ruddell, RB, MR Ruddell \& M Singer (Eds), Theoretical models and processes of reading. Newark: International Reading Association. 414-447.

STANOVICH, KE. 1986. Matthew effects in reading: Some consequences of individual differences in the acquisition of literacy. Reading Research Quarterly, 21:360-406.

WEBBER, BL. 1980. Syntax beyond the sentence: Anaphora. In Spiro RJ, BC Bruce \& WF Brewer (Eds), Theoretical issues in reading comprehension. Hillsdale: Lawrence Erlbaum.

WESSELS, N. 2010. School Libraries as a literacy intervention tool in primary schools: Action research in Atteridgeville. Unpublished master's dissertation. Pretoria, University of South Africa.

WOLF, M. 2008. Proust and the squid. Cambridge: Icon Books.

WOLF, M \& T KATZIR-COHEN. 2001. Reading fluency and its intervention. Scientific Studies of Reading, 5(3):211-239.

\section{BIOGRAPHICAL NOTE}

Prof. Elizabeth Pretorius is a lecturer at Unisa, Department of Linguistics. Her research interests include examining the relationship between language, cognition, reading ability and literacy skills. E-mail address: pretoej@unisa.ac.za

Dr Mirriam Lephalala is a lecturer at Unisa, Department of English Studies. Her areas of research include language teaching, learning, assessment and literacy.

E-mail address: lephammk@unisa.ac.za 


\title{
Appendix A: Typical lesson plan for Phase A \\ BOOK CLUB: We're going on a bear hunt
}

\author{
13 March 2008
}

In the previous book club meeting the focus was on having fun with a story book while at the same time introducing the learners to the basic elements of a story. In this lesson we build on this knowledge, and give learners further practice in identifying elements in a story in a fun way, but at the same time they learn about onomatopoeic words in English (i.e. words that imitate the sound they represent, e.g. Plop! Whoosh! Buzz!)

\section{Aims:}

- Read to the learners the story We're going on a bear hunt to practise identifying the basic elements of a story (elements = characteristics, features, properties).

- Use the story to teach them a long word, viz. onomatopoeia, and some onomatopoeic words in English in a fun way (from the Greek onoma = name; poieo = to make).

Outcomes: By the end of the lesson the learners should be able to do the following:

Identify the following elements in the story:

- title and author

- characters (main and secondary)

- setting (place, time)

- problem in the story (minor and main problem)

- action

- outcomes (resolution of problem).

Remember at least 5 onomatopoeic words in English and know what sounds/actions they represent.

Materials: Storybook We're going on a bear hunt; Photostat the story and give each group a page to read. Bring some pictures of bears to class (either from a book or downloaded from the Internet)

\section{Steps}

1. Activate the learners' background knowledge by asking them if they know what a bear is and if they've ever seen one. Show them a picture of a bear. Explain that bears live in caves in cold places such as the USA, Canada, Russia, etc.

2. Preview the book and the title: show the cover to the class, discuss the title, author, ask them what they think the story will be about from the picture, etc.

3. Remind the learners of the main elements of a story (i.e. briefly go over last week's main points).

4. Ask the class to be quiet and attentive while you read the story to them. Read the story, putting in as much feeling as possible. Show them the pictures as you turn each page.

5. At the end, discuss with the learners what they think the purpose of the story is. (Not necessarily a right answer here: Showing how parents and children can have fun together; stimulating the imagination; having fun with language through repetition, play on words).

6. Identify the story elements. The characters (main characters $=$ the father, 4 children, 
one of whom is still quite small).

The problem $=$ the father and children go for a walk, looking for a bear to hunt, pretending that they're going to hunt a bear.

action = they go through grass, a river, mud, a forest, a snowstorm, until they come to a cave. Inside the cave is a bear!

resolution $=$ they all get a big fright and run home fast, the way they came. They lock their door and jump into bed.

7. Arrange the class into their 6 groups and give each group a Photostat of a page from the story.

8. Read the story again, and let each group take a turn to read their page at the appropriate time.

9. Afterwards, write the onomatopoeic words on the board. Ask each group to write the NS equivalent, if possible. Point out that these words are often used in poetry and in comics.

10. They must write the new words into their book club book.

11. Ask the class to tell you what feelings they had when they listened to or read the story (e.g. When I listened to the story I ..... felt happy/wanted to laugh/enjoyed myself/had fun/felt motivated ... There are no right or wrong answers here. Try and see what the children come up with! Let them get used to talking about how they felt about the story.

12.

\section{Homework}

- Obligatory: Learners must learn the new onomatopoeic words for homework. They must also find out and bring two new onomatopoeic words to class for book club next term.

- There will be a prize for the first learner called forward at random who can spell the word onomatopoeia correctly on the chalkboard and say what it is!

- Optional homework for the holidays: Learners who are library members can ask the librarian at the community library to help them look for a fun story that they can read to their mother/father/younger brother or sister during the holidays.

\section{Appendix B: Typical lesson plan for Phase B}

Using stories to learn about countries around the world.

\section{BOOK CLUB: The best teacher}

28 May 2008

In the previous book club meeting we read a story from Ghana, Africa. This week we read a story from Eastern Europe, Romania.

In this lesson we build on prior storybook reading practice by working on vocabulary, drawing attention to identifying elements in a story in a fun way, talking about the theme of the story

Aims: 
- Identify on the map the country of origin of the story

- Read to the learners the story The best teacher to practise identifying the basic elements of a story (elements $=$ characteristics, features, properties).

- Identify the theme/moral of the story.

- Use the story to build vocabulary and enter new words on word cards

Outcomes: By the end of the lesson the learners should be able to do the following:

$>$ Make inferences about the characters in the story from looking at the pictures in the text

$>$ Make inferences about what may happen in the story from looking at the pictures

$>$ Identify the following elements in the story:

- title and author

- characters (main and secondary)

- setting (place, time)

- problem in the story (minor and main problem)

- action

- outcomes (resolution of problem)

- moral of story.

Write down in book club book 8 new words from the story and learn them.

Idiom: Necessity is the mother of invention

necessity - botlhokwa; something that is needed $\quad$ worn out tired

lad young boy useless opposite of useful

rickety wobbly, not strong timber wood

axle bar to which wheels are connected

harness (n) leather straps used to tie animal to a cart; (v) tie animal to cart with leather

straps

Materials: Storybook The best teacher; Photostatted copies of the story to be pasted into books

Steps

1. Ask learners to identify Europe on the map and then find Romania.

2. To activate background schemas, ask learners if they know about Dracula stories - which originally come from Romania.

3. Preview the book and the title: show the cover to the class, discuss the title, author, ask them what they think the story will be about from the picture, etc.

4. Pre-teach the 8 new words. Write them on the board and ask learners to look up meanings, which are then written on the board. Learners to write words and meanings in their books.

5. Remind the learners of the main elements of a story (i.e. briefly go over previous week's main points).

6. Arrange the class into 6 groups and give each group a Photostatted page from the story.

7. Ask the class to be quiet and attentive while you read the story to them. Read the story, putting in as much feeling as possible.

8. Ask the groups if there are any words whose meanings they want to know. Members of groups take turns to write their words and the chalkboard and meanings looked up in 
dictionary and shared. English and N Sotho meanings written on chalkboard.

9. Read the story again, with each group taking turns to read a paragraph from their page.

10. Discuss with the learners what they think the moral of the story is. (They must use the title - who is the best teacher and who was the learner? What was the lesson the 'teacher' taught?)

11. Identify the story elements. The characters (main characters = the son and father; they lived well and happily and had no problems).

The problem $=$ the father was worried that his son would not know how to deal with problems in life.

action $=$ the son was sent into the forest to collect wood with a cart and two oxen. Father says that necessity will help his son if anything goes wrong. Axle breaks. Son calls for Necessity but no-one comes so fixes cart himself.

resolution $=$ the son learns an important lesson about independence - not waiting for people to do things for you but doing them for yourself.

\section{Homework}

- Learners must learn the new words for homework.

- Learners to listen to the news and find a story that comes from a country in Europe. Come and tell class about news item and identify the country on the map.

\section{APPENDIX C: Book club rules}

1. When the period starts, get into your reading group, quietly and quickly.

2. Take out your book club book and a pencil/pen.

3. The group leaders will hand out the books/text to you as well as the containers with scissors and glue and vocabulary cards.

4. Cut out the text and paste it into book club book quickly and quietly.

5. When you are asked to read a short story or text, read a paragraph at a time. Everyone in the group reads the same paragraph quietly to himself/herself for a few minutes.

6. After the reading time is up, identify words that you don't know, share them with the group and look up their meanings in a dictionary.

7. Write five words that you don't know in your vocabulary list in the Book Club book. Do so quickly and correctly. Write their meanings in North Sotho or English. The group leader writes them on the small cards each week.

8. Now take turns for each one to read a paragraph aloud once the words have been discussed. Help each other with pronouncing difficult words or put up your hand to ask for help.

9. When all the paragraphs have been read and words discussed, read the whole text quietly to yourself from beginning to end, paying attention to meaning.

Golden rule: It is difficult to learn and concentrate when there is lots of noise - You may not shout or talk loudly in class. Talk quietly and treat your peers with respect. 